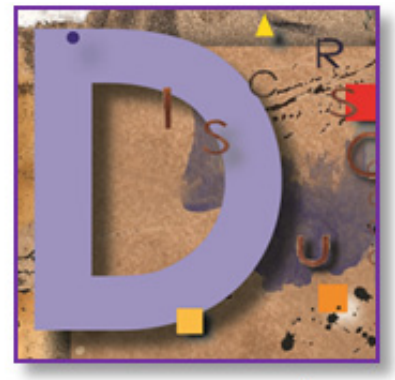

DISCURSOS CONTEMPORÄNEOS

EM

ESTUDO

ISSN 2237-7247

\section{A CONSTRUÇÃO DO IDEAL IDENTITÁRIO BRASILEIRO PELA PUBLICIDADE GOVERNAMENTAL - UMA ANÁLISE CRÍTICA MULTIMODAL}

Este estudo tem por objetivo interpretar, por meio de um vídeo institucional do governo brasileiro, as relações entre recursos semióticos, geradores de sentido, e a construção de representações ideais de uma comunidade, facilitadoras da prática governamental de controle social. Assim, com a pesquisa sobre a construção do ideal identitário brasileiro, por meio da publicidade, observamos como esses recursos se relacionam de forma integrada para reafirmar esse ideal, ideologicamente construído e cuidadosamente cultivado pelos discursos, segundo o enfoque da Semiótica Social da Multimodalidade (TSSM), proposto por Gunther Kress, em 2010, pela Análise de Discurso Crítica (ADC), especialmente a versão proposta por Fairclough em 2003, e pela Linguística Sistêmico-Funcional (LSF), criada por Halliday, dando relevo ao fato observado pelas pesquisadoras de que uma teoria como a $\mathrm{ADC}$ pode responder à pergunta “por quê?" e a TSSM e a LSF podem responder à indagação “como?”. Este estudo faz parte de uma pesquisa maior sobre publicidade governamental no Brasil. Como considerações finais, podemos dizer que o governo brasileiro está direcionado politicamente para a construção do ideal identitário brasileiro, com o estabelecimento de um envolvimento emocional acrítico entre os cidadãos, por meio da transmissão da ideologia de inclusão social.

Palavras-Chave: Multimodalidade. Semiótica social. Recursos semióticos. Ideal identitário brasileiro.

\title{
Introdução
}

Esta pesquisa faz parte de uma pesquisa maior, direcionada à compreensão ampliada acerca do papel do Estado brasileiro na formação de visões de mundo, de figuras-símbolos ideologicamente construídas, alocadas no lugar da identidade ideal. Como parte dela, este artigo se concentra na análise de um vídeo institucional do governo brasileiro, intitulado $\mathrm{O}$

\footnotetext{
${ }^{1}$ Universidade de Brasília (UnB). Departamento de Linguística, Português e Línguas Clássicas. Programa de Pós-Graduação em Linguística. Brasília-DF. Brasil. E-mail: josenia.unb@gmail.com.

${ }^{2}$ Universidade de Brasília (UnB). Departamento de Linguística, Português e Línguas Clássicas. Brasília-DF. Brasil. Programa de Pós-Graduação em Linguística.E-mail:mayared@gmail.com.
} 
Brasil está em boas mãos, com duração de trinta segundos. Essa peça publicitária foi veiculada na televisão (TV aberta e TV a cabo) entre outubro e dezembro de 2011, no horário dito nobre, entre $20 \mathrm{~h}$ e $22 \mathrm{~h}$. Esse horário aumenta o poder de alcance do comercial, uma vez que, nele, a maioria dos trabalhadores brasileiros se encontra em sua residência, descansando de mais um dia de trabalho intenso. Foram analisados 24 quadros (frames), os mais representativos para o significado da peça publicitária.

O texto publicitário tem um poder muito grande de persuasão porque seus criadores/ autores/meaning-makers sabem escolher o recurso semiótico necessário para realizar o enquadramento ideal a fim de direcionar a percepção do observador/leitor/viewer e, dessa forma, garantir a empatia do viewer com o mundo retratado. Assim, é necessário que os analistas de discurso busquem novas formas de estudos de transcrições e de análises desse tipo de texto multimodal, o filme publicitário, visto que o seu papel na manutenção e na perpetuação das relações de poder é muito significativo.

\section{A Teoria da Semiótica Social da Multimodalidade - o princípio de integração dos recursos semióticos na metodologia da transcrição}

A teoria desenvolvida por Kress - Teoria Semiótica Social da Multimodalidade (TSSM) - apõe uma nova lente aos fatos ligados às práticas comunicacionais humanas. Essa teoria, por ser uma teoria semiótica, preocupa-se, acima de tudo, com o sentido. Ademais, é social porque entende que os recursos semióticos — os fios de tecer o sentido do texto — são moldados e perpetuados cultural e historicamente em uma comunidade. Essa teoria leva em consideração que a comunicação humana não se resume ao modo fala, ou ao modo escrita, mas que se utiliza também de vários modos de expressão para construir o sentido de um textomensagem. Assim, a tarefa do analista de um texto multimodal, como um filme publicitário, é também observar como a disposição dos recursos semióticos, dispostos dinamicamente, facilita a produção deste ou daquele sentido.

Existem alguns conceitos fundamentais na TSSM, construto que privilegia a comunicação e o interesse do meaning maker (autor do texto, literalmente "fazedor de significado"), em usar determinados modos para expressar o sentido desejado com o objetivo de transmitir esse sentido para os outros, sejam viewers, leitores ou ouvintes. Em multimodalidade, existe o conceito de interesse: o autor do texto tem um sentido a transmitir e escolhe os recursos semióticos para formar o seu texto, de acordo com o seu interesse. Temos o conceito de modo: recursos que materializam o sentido de um texto, como o modo escrita, o modo gestual, o modo fala, o modo cor. Modos pertencem ao plano da expressão. Segundo o modelo de Hjelmslev, foram moldados social e culturalmente e estão disponíveis para o meaning maker construir o seu texto. 
Esta pesquisa está ancorada na TSSM proposta por Gunther Kress, na Análise de Discurso Crítica (ADC) - aparato teórico desenvolvido por Fairclough em 2003 -, e na Linguística Sistêmico-Funcional (LSF) criada por Halliday. Dá relevo ao fato observado pelas pesquisadoras de que uma teoria como a ADC pode responder à pergunta "por quê?" e de que a TSSM e a LSF podem responder à indagação "como?". As categorias de análise a serem utilizadas são as seguintes: modo fala, modo escrita, modo cor e cinestesia, qual seja, o movimento corporal. Em relação à $\mathrm{ADC}$, será utilizada a categoria referente ao significado representacional do discurso, basicamente, a representação dos eventos e dos atores sociais, com o intuito de localizar os discursos que estão por trás da letra da canção no comercial em questão. Pretendemos observar como essas peças publicitárias são construídas pelo meaningmaker (autor do texto) e de que forma servem ao trânsito das ideologias e ao controle social pelo Estado.

A transcrição do filme será feita por meio do modelo (tabela/matriz) de Baldry e Thibault, que deixa explícito o princípio da integração dos recursos semióticos em um texto. (BALDRY; THIBAULT, 2010). Com a transcrição, pode-se ver, ao longo das linhas da tabela, os recursos semióticos utilizados simultaneamente. Foram analisados 24 frames de um filme de 30 segundos. Trata-se dos frames mais significativos, cada um contendo o personagem típico do quadro, seja esse personagem representado por meio do trabalho que faz com as mãos, seja por meio de sua ação com o corpo inteiro.

O filme inicia-se com uma representação metonímica, pela qual o participante (todo) é representado pela parte (mãos). O comercial compõe-se de uma sequência de mini-histórias, com participantes típicos da paisagem cultural brasileira arquetípica (samba + futebol + sorriso). Nesta pesquisa, escolhemos of frame representativo de cada personagem. Cada linha será composta das seguintes subdivisões ou colunas: o tempo em segundos (T), no qual o enquadramento foi realizado; os frames narrativos; a imagem visual (posição da câmera); a trilha sonora; o modo escrita; e o movimento corporal (cinestesia). No caso da coluna referente à trilha sonora, serão usados símbolos para identificar a voz feminina; no caso da coluna relativa ao movimento corporal, a notação entre colchetes indica ações simultâneas, separadas por ponto e vírgula. Se a ação for sequencial, faremos a anotação com o símbolo do acento circunflexo $\left({ }^{\wedge}\right)$.

Para a análise dos textos, será utilizada a Gramática Sistêmico-Funcional (HALLIDAY, 2004) em relação ao sistema de transitividade e à metafunção interpessoal da linguagem, a fim de entender que um texto publicitário pode constituir, na verdade, um texto de ordem ou de pedido: implícita ou explicitamente, o texto publicitário dá uma ordem (de consumo ou de adesão a um ideal) ou faz um pedido (para consumir ou para aderir a um ideal ou a uma visão de mundo).

A Análise de Discurso Crítica (FAIRCLOUGH, 2003) será utilizada como ferramenta para a análise discursiva com o intuito de explicitar o desvelamento das ideologias por meio dos significados textuais. 


\section{Análise do vídeo institucional - identificação patriótica e envolvimento acrítico}

No texto O Brasil está em boas mãos, é apresentada, ao viewer (observador, telespectador), uma sequência de imagens com vários personagens brasileiros dançando ao som de um samba, celebrando as "oportunidades" que o País está oferecendo especialmente às pessoas com menos recursos. Os participantes convidam o observador a fazer parte do mundo retratado por meio do sorriso, invocando, nessa interação, os chamados valores culturais do brasileiro.

O texto é composto de imagens em movimento, de pessoas sambando e celebrando, de canção com letra, de narração em primeiro plano com uma voz feminina - e sua respectiva legenda embaixo da imagem, sem ligação com a imagem — e de chamadas escritas em cima das imagens, que mostram dados estatísticos referentes ao crescimento econômico do Brasil. A voz feminina aparece pouco depois do início do samba, e os dados, pouco depois do início da narração da voz feminina. Esse texto foi veiculado na TV aberta e na TV por assinatura em novembro e dezembro de 2011. Segundo a Secom (Secretaria de Comunicação da Presidência da República), ele mostra o protagonismo dos brasileiros no desenvolvimento do Brasil.

\section{A tabela de transcrição - uma visão diferente}

O modelo de transcrição matricial (linhas e colunas) de textos dinâmicos, como um filme publicitário, proposta por Baldry e Thibault (2010), permite-nos uma percepção linear diferenciada do texto, o que deixa explícito o princípio da integração dos recursos semióticos, ou seja, podemos ver como todos os recursos semióticos estão dispostos para a formação dos sentidos do texto.

A tabela de transcrição antecipa, emalgumamedida, a análise.Quandorecontextualizamos o dado, permitimos que seja visto como os recursos semióticos foram dispostos pelo meaning maker (autor) para formar o sentido. Essa disposição linear dos recursos semióticos fornece uma lente capaz de mostrar o que não podemos perceber ao vermos o filme, cujos quadros passam muito rapidamente, às vezes, escapando à nossa percepção consciente.

A legenda é a que segue:

- T: tempo em segundos (o momento do filme em que apareceu determinado quadro; às vezes, vários quadros apareceram no mesmo segundo)

- PC: posição da câmera (E: estacionária)

- PH: perspectiva horizontal (frontal ou oblíqua)

- PV: perspectiva vertical (alta, baixa, mesmo nível)

- D: distância entre o viewer e o mundo retratado (muito perto, perto, médio close, tomada de longe) 
- $\quad \mathrm{CV}$ : colocação visual

- SV: saliência visual

- FV: foco visual

- CR: cor em realce

Um frame visual significativo foi escolhido. Com isso, identificamos em que momento (segundo) do filme esse frame comparece. Normalmente, cada frame visual coincide com diferentes personagens, mas nem sempre isso ocorre. Por exemplo, no caso do gari sambando, dos "peladeiros", da mãe segurando o filho. Esses personagens tiveram mais tempo no total do filme.

A posição da câmera (PC) é estacionária durante todo o filme. Na perspectiva horizontal $(\mathrm{PH})$, prevalece a posição frontal da câmera e, na perspectiva vertical $(\mathrm{PV})$, prevalece a câmera no mesmo nível dos personagens. Em relação à distância $\mathrm{D}$ (distância entre e o viewer e o mundo retratado), o filme começa com closes fechados nas mãos, passa por médios closes (cintura para cima) e termina em um close fechado das palmas das mãos.

A seguir, temos a matriz de transcrição da peça publicitária com os principais frames visuais, formadores de pequenos grupos significativos.

Quadro 1 - As Metáforas das Mãos - a construção do Brasil

\begin{tabular}{|c|c|c|c|c|c|c|}
\hline $\mathbf{T}$ & $\begin{array}{l}\text { FRAME VISUAL } \\
\text { (coincide com as tomadas) }\end{array}$ & $\begin{array}{l}\text { IMAGEM } \\
\text { VISUAL }\end{array}$ & $\begin{array}{l}\text { TRILHA } \\
\text { SONORA } \\
\text { Samba }\end{array}$ & $\begin{array}{l}\text { VOZ } \\
\text { FEMININA }\end{array}$ & $\begin{array}{l}\text { TEXTO } \\
\text { MODO } \\
\text { ESCRITA } \\
\text { NA } \\
\text { IMAGEM }\end{array}$ & $\begin{array}{l}\text { MOVIMENTO } \\
\text { CORPORAL }\end{array}$ \\
\hline 1 & & $\begin{array}{l}\text { PC: E } \\
\text { PH: } \\
\text { oblíqua } \\
\text { PV: mediana } \\
\text { D: muito } \\
\text { perto } \\
\text { CV: paisagem } \\
\text { agrícola. } \\
\text { SV: mãos, } \\
\text { caixinha de } \\
\text { fósforo }\end{array}$ & $\begin{array}{l}\text { Som } \\
\text { introdutório do } \\
\text { cavaquinho; } \\
\text { depois, o } \\
\text { tambor e o } \\
\text { pandeiro. Som } \\
\text { da caixa de } \\
\text { fósforo. }\end{array}$ & & & $\begin{array}{l}\text { Mãos de homem } \\
\text { batucando na } \\
\text { caixinha de } \\
\text { fósforo. }\end{array}$ \\
\hline
\end{tabular}




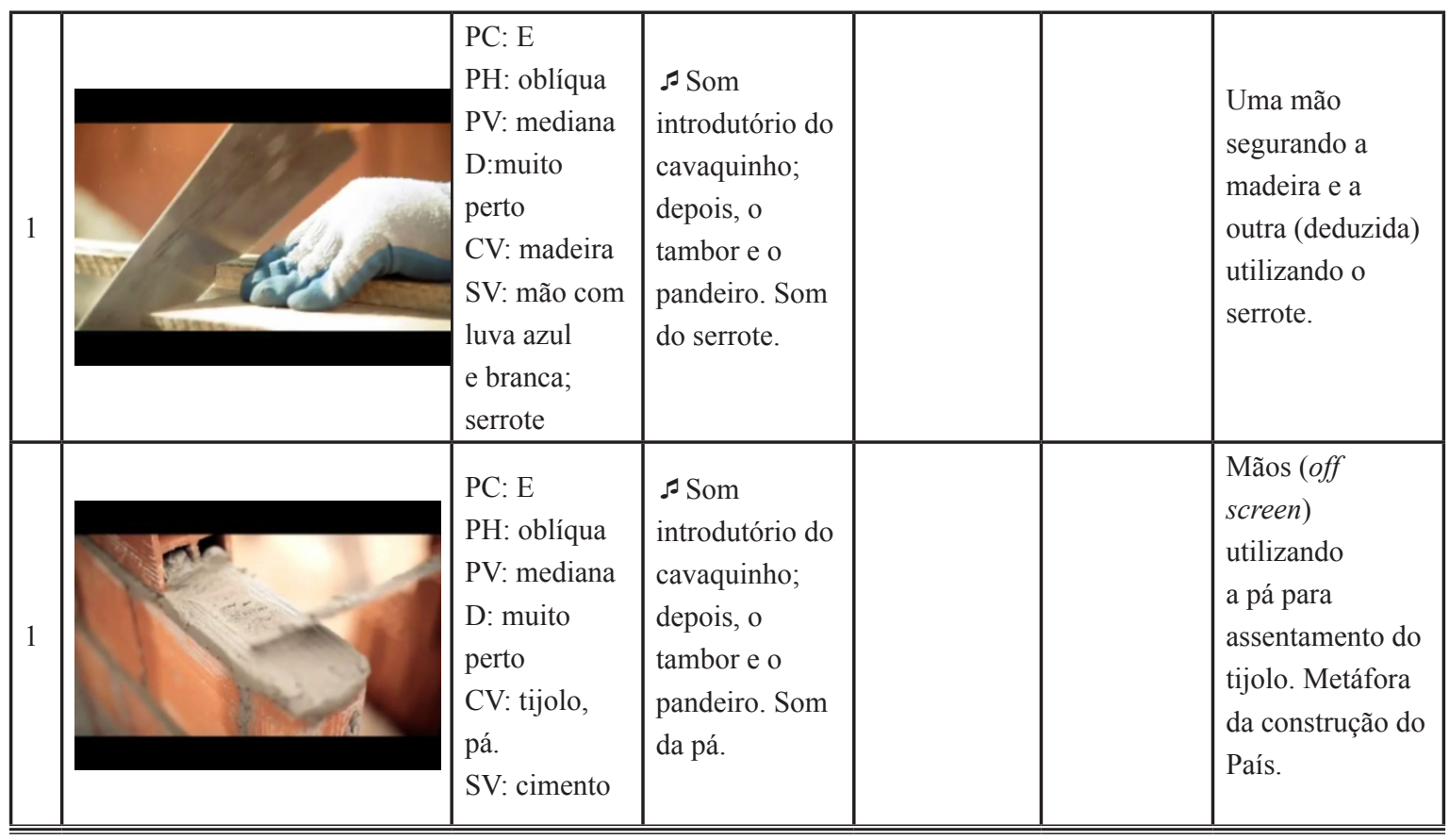

A construção do Brasil é representada pelo trabalho com as mãos. A câmara está em close, amplificando o papel do trabalho na construção do País. Há uma significação metonímica do Brasil (parte pelo todo): as mãos dos brasileiros são o Brasil, e uma metáfora de construção/ crescimento: as mãos dos brasileiros vão construir o Brasil e o País vai crescer.

Nesse caso, o Brasil encontra-se metaforicamente conectado à produção agrícola (rapidamente, no primeiro frame visual); à construção civil (mais representativa) e às atividades de produção de bens e serviço dos microempresários (também representativa).

\section{O gari: a coreografia solitária do trabalhador feliz}

Quadro 2-O gari: a felicidade do fim de festa

\begin{tabular}{|c|c|c|c|c|c|c|}
\hline & $F R A M E$ VISUAL & IMAGEM VISUAL & $\begin{array}{l}\text { TRILHA } \\
\text { SONORA }\end{array}$ & $\begin{array}{l}\text { VOZ } \\
\text { FEMININA }\end{array}$ & $\begin{array}{l}\text { MODO } \\
\text { ESCRITA }\end{array}$ & $\begin{array}{l}\text { MOVIMENTO } \\
\text { CORPORAL }\end{array}$ \\
\hline 3 & & $\begin{array}{l}\text { PC: E } \\
\text { PH: oblíqua } \\
\text { PV:mediana } \\
\text { D: médio close } \\
\text { CV: fundo verde e } \\
\text { branco } \\
\text { SV: sombra do gari } \\
\text { CR: verde }\end{array}$ & $-\lambda$ Em boas & & & $\begin{array}{l}\text { Sombra do } \\
\text { personagem que } \\
\text { vai aparecer } \\
\text { (clima de } \\
\text { suspense para } \\
\text { apresentar o } \\
\text { "sambista do } \\
\text { Brasil"). }\end{array}$ \\
\hline
\end{tabular}




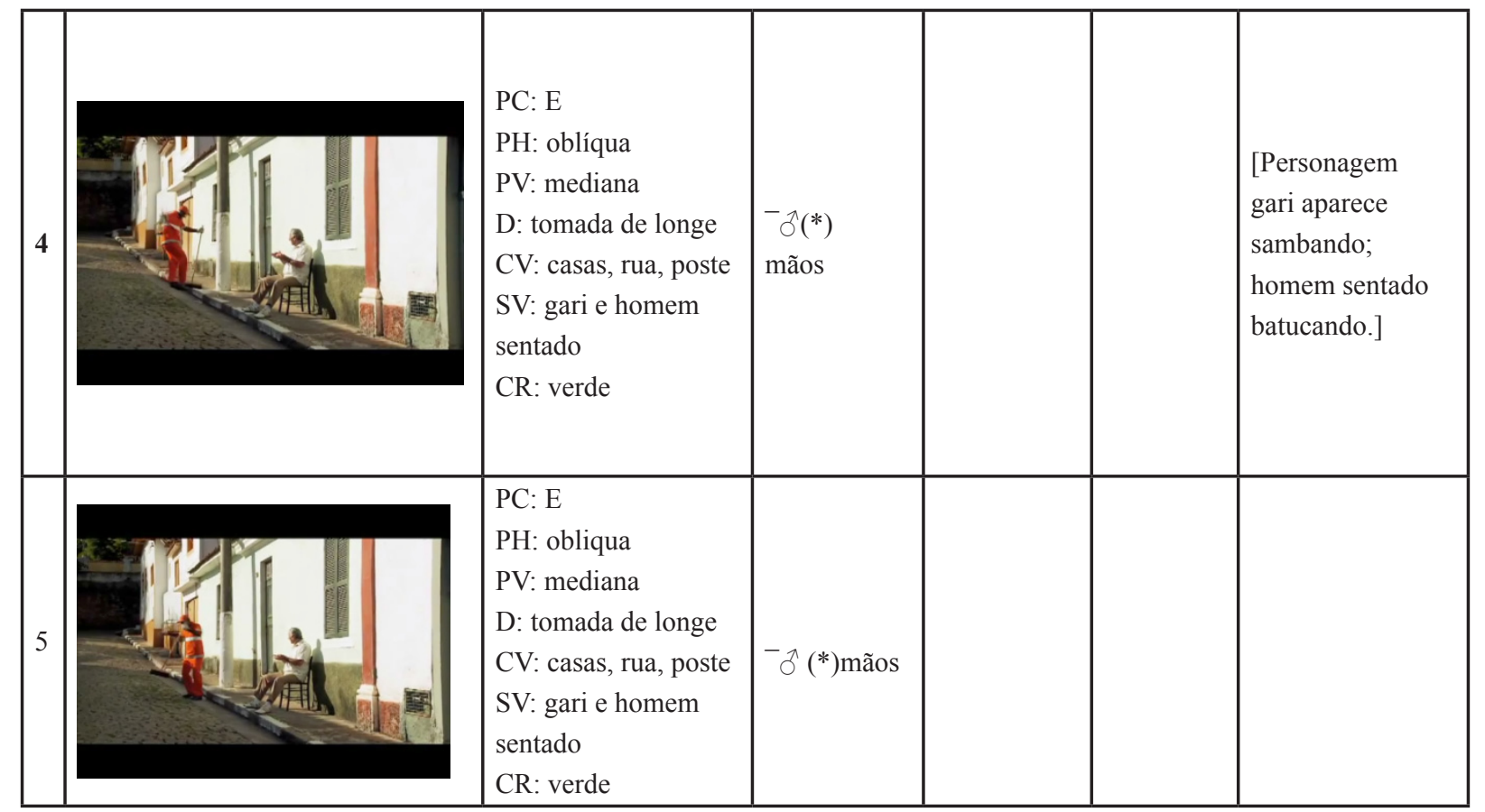

O gari é símbolo do samba, da alegria ao trabalhar; é o varredor da imensa área do sambódromo completamente abarrotada de lixo após o carnaval. $\mathrm{O}$ gari prolonga a festa do carnaval, porque também representa um tipo de "bloco" que desenvolve coreografias para um sambódromo vazio e cheio de restos da grande comemoração. No caso da peça publicitária em análise, há um público para a dança do gari, representado por um aposentado típico, sentado em uma cadeira colocada fora da casa, em um bairro tranquilo de um Brasil que não existe. $O$ texto torna o gari protagonista desse ideal de Nação, além de realizar o paralelo entre trabalho e alegria - todos os trabalhadores estão alegres em trabalhar, em alcançar as suas metas, que são as metas do Brasil. Na linguagem de Fairclough (2003), o gari é um "caractere social" ou um "tipo social". Trata-se de uma das possíveis identidades sociais do Brasil. Podemos ver que esse "caractere social" é construído pela mídia de massa como um ser alegre, amável, 
bem-humorado. Segundo o nosso entendimento, esse tipo social é um tópico-auxiliar da governança, porque permite a propagação da ideia de um brasileiro amável e risonho frente a qualquer situação da vida, o que está muito distante da realidade.

\section{A pelada com os amigos: a alegria do fim de semana}

Quadro 3 - A pelada (partida de futebol não profissional) com amigos no fim de semana

\begin{tabular}{|c|c|c|c|c|c|c|}
\hline $\mathrm{T}$ & FRAME VISUAL & IMAGEM VISUAL & $\begin{array}{l}\text { TRILHA } \\
\text { SONORA }\end{array}$ & $\begin{array}{l}\text { VOZ } \\
\text { FEMINIA }\end{array}$ & $\begin{array}{l}\text { MODO } \\
\text { ESCRITA }\end{array}$ & $\begin{array}{l}\text { MOVIMENTO } \\
\text { CORPORAL }\end{array}$ \\
\hline 7 & F. & $\begin{array}{l}\text { PC: E } \\
\text { PH: frontal } \\
\text { PV: mediana } \\
\text { D: média } \\
\text { CV: rede de goleiro ao } \\
\text { fundo } \\
\text { SV: jogadores } \\
\text { CR: verde } \\
\text { FV: longe }\end{array}$ & $\begin{array}{l}\text { ADo povo } \\
\text { brasileiro }\end{array}$ & & & $\begin{array}{l}\text { [Jogadores em } \\
\text { coreografia; } \\
\text { sorriso] }\end{array}$ \\
\hline 8 & & $\begin{array}{l}\text { PC: E } \\
\text { PH: frontal } \\
\text { PV: mediana } \\
\text { D: média } \\
\text { CV: rede de goleiro ao } \\
\text { fundo } \\
\text { SV: jogadores } \\
\text { CR: verde } \\
\text { FV: longe; viewer }\end{array}$ & & & & $\begin{array}{l}\text { Jogadores } \\
\text { desenvolvem a } \\
\text { coreografia. }\end{array}$ \\
\hline
\end{tabular}

A "pelada do fim de semana" é a marca (talvez não registrada) do lazer do homem brasileiro médio, pai de família, na faixa dos quarenta aos cinquenta anos de idade, frequentador do campo de futebol comunitário nos fins de semana, outro caractere social, ou tipo social, caracterizado pela alegria, pela paixão, pela cerveja e pelo futebol, embora a sua atividade física normalmente se resuma a essa partida semanal de 30 ou 40 minutos. $O$ papel do sorriso como um elemento de coesão textual pode ser observado ao longo de todo esse comercial. 


\section{O trabalho mais qualificado e o consumo ao alcance da população}

\section{Quadro 5 - A inclusão e o consumo}

\begin{tabular}{|c|c|c|c|c|c|c|}
\hline $\mathrm{T}$ & FRAME VISUAL & IMAGEM VISUAL & $\begin{array}{l}\text { TRILHA } \\
\text { SONORA } \\
\end{array}$ & $\begin{array}{l}\text { VOZ } \\
\text { FEMININA } \\
\end{array}$ & $\begin{array}{l}\text { MODO } \\
\text { ESCRITA } \\
\end{array}$ & $\begin{array}{l}\text { MOVIMENTO } \\
\text { CORPORAL } \\
\end{array}$ \\
\hline 10 & & $\begin{array}{l}\text { PC: E } \\
\text { PH: frontal } \\
\text { PV: baixa } \\
\text { D: média } \\
\text { CV: céu, arranha-céu, } \\
\text { carregador de mala } \\
\text { SV: homem } \\
\text { recepcionista }\end{array}$ & $\begin{array}{l}\text { música ao } \\
\text { fundo; } \\
\text { solista } \\
\text { masculino } \\
- \text { O } \\
\text { Brasil }\end{array}$ & $\begin{array}{l}\text { }+ \text { — Tá todo } \\
\text { mundo }\end{array}$ & & $\begin{array}{l}\text { (Recepcionista } \\
\text { batucando } \\
\text { com as mãos; } \\
\text { sorriso) }\end{array}$ \\
\hline 11 & & $\begin{array}{l}\text { PC: E } \\
\text { PH: oblíqua } \\
\text { PV: alta } \\
\text { D: média } \\
\text { CV: banco com } \\
\text { bolsa, outros clientes } \\
\text { SV: moça de preto }\end{array}$ & $\begin{array}{l}\text { - JTá forte } \\
\text { e tá }\end{array}$ & $\stackrel{+}{\text { \& celebrando }}$ & & $\begin{array}{l}\text { (Mulher } \\
\text { sambando } \\
\text { na sapataria; } \\
\text { sorriso) }\end{array}$ \\
\hline
\end{tabular}

Nesse quadro, podemos perceber uma antinomia do ângulo da câmera: no primeiro quadro, o viewer (telespectador, observador) está abaixo do nível dos olhos do participante, o que pode indicar um empoderamento da etnia negra no Brasil, uma vez que o ângulo da câmera revela o tipo de interação social, que pode ser igualitária (perspectiva vertical mediana) ou não igualitária (perspectiva vertical alta ou baixa). No quadro seguinte, a consumidora na sapataria está enquadrada como estando abaixo dos olhos do viewer, o que sugere uma relação assimétrica de poder entre a consumidora de sapato (visão estereotipada da configuração de consumo da mulher) e o observador. 


\section{O Brasil é um bebê que cresce em nossas mãos}

Quadro 6-O crescimento humano, educacional e profissional

\begin{tabular}{|c|c|c|c|c|c|c|}
\hline $\mathrm{T}$ & FRAME VISUAL & $\begin{array}{l}\text { IMAGEM } \\
\text { VISUAL }\end{array}$ & $\begin{array}{l}\text { TRILHA } \\
\text { SONORA }\end{array}$ & $\begin{array}{l}\text { VOZ } \\
\text { FEMININA }\end{array}$ & $\begin{array}{l}\text { MODO } \\
\text { ESCRITA }\end{array}$ & $\begin{array}{l}\text { MOVIMENTO } \\
\text { CORPORAL }\end{array}$ \\
\hline 12 & & $\begin{array}{l}\text { PC: E } \\
\text { PH: oblíqua } \\
\text { PV: mediana } \\
\text { D: close shot } \\
\text { CV: fundo } \\
\text { amarelo } \\
\text { SV: mãe e } \\
\text { bebê } \\
\text { FV: vetor do } \\
\text { olhar liga mãe } \\
\text { e bebê; perto }\end{array}$ & $\begin{array}{l}-\bar{\delta} \\
\text { Guerreiro }\end{array}$ & $\begin{array}{l}\text { }+ \text { O Brasil } \\
\text { cresce }\end{array}$ & & $\begin{array}{l}\text { [Mulher } \\
\text { levantando } \\
\text { bebê; sorriso] }\end{array}$ \\
\hline 13 & & $\begin{array}{l}\text { PC: E } \\
\text { PH: oblíqua } \\
\text { PV: mediana } \\
\text { D: close shot } \\
\text { CV; fundo } \\
\text { amarelo } \\
\text { SV: mãe e } \\
\text { bebê } \\
\text { FV: vetor do } \\
\text { olhar liga mãe } \\
\text { e bebê; perto }\end{array}$ & 更 & $\begin{array}{l}\text { } \subseteq \text { Brasil } \\
\text { cresce }\end{array}$ & & $\begin{array}{l}\text { [Mulher } \\
\text { levantando } \\
\text { bebê; sorriso] }\end{array}$ \\
\hline 14 & & $\begin{array}{l}\text { PC: E } \\
\text { PH: frontal } \\
\text { PV: baixa } \\
\text { D: medium } \\
\text { close shot } \\
\text { CV: céu azul e } \\
\text { faixas laranjas } \\
\text { SV: formandos }\end{array}$ & & $\begin{array}{l}\text { } \\
+ \text {-Com } \\
\text { (*) mais } \\
\text { oportunidades }\end{array}$ & & $\begin{array}{l}\text { Formandos } \\
\text { jogando o } \\
\text { chapéu }\end{array}$ \\
\hline
\end{tabular}

Aqui, podemos observar a construção da identidade entre o Brasil e o bebê, que está crescendo, enfocando a necessidade de investimentos e de trabalho para o desenvolvimento do País e exemplificando com os diplomas ("canudos") jogados para cima após a formatura. É relevante atentarmos para a integração semiótica entre o texto da voz da narradora $(O$ Brasil cresce) e a ação da mãe erguendo o bebê. No caso, o crescimento fica redundantemente expresso, sinalizando para a construção da identidade almejada pelo autor do texto. 


\section{Os números que descrevem o Brasil}

Quadro 7-OAcesso ao Crédito para Empreendedorismo, Formação Técnica e Educação Inclusiva

\begin{tabular}{|c|c|c|c|c|c|c|}
\hline $\mathrm{T}$ & FRAME VISUAL & $\begin{array}{l}\text { IMAGEM } \\
\text { VISUAL }\end{array}$ & $\begin{array}{l}\text { TRILHA } \\
\text { SONORA }\end{array}$ & $\begin{array}{l}\text { VOZ } \\
\text { FEMININA }\end{array}$ & $\begin{array}{l}\text { MODO } \\
\text { ESCRITA }\end{array}$ & $\begin{array}{l}\text { MOVIMENTO } \\
\text { CORPORAL }\end{array}$ \\
\hline 16 & 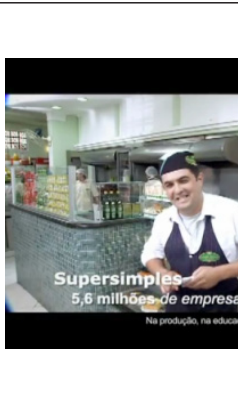 & $\begin{array}{l}\text { PC: E } \\
\text { PH: frontal } \\
\text { PV: mediana } \\
\text { D: média } \\
\text { CV: balcão com } \\
\text { pães } \\
\text { SV: padeiro; } \\
\text { texto } \\
\text { FV: mediano }\end{array}$ & ${ }^{-}$¿Do povo & $\begin{array}{l}+- \\
\text { Na produção }\end{array}$ & $\begin{array}{l}\text { Supersimples: } \\
5,6 \text { milhões } \\
\text { de empresas } \\
\text { beneficiadas }\end{array}$ & $\begin{array}{l}\text { [Padeiro } \\
\text { batucando; } \\
\text { sambando; boca: } \\
\text { sorriso] }\end{array}$ \\
\hline 17 & & $\begin{array}{l}\text { PC: E } \\
\text { PH: oblíqua } \\
\text { PV: mediana } \\
\text { D: média } \\
\text { CV: outros } \\
\text { estudantes } \\
\text { SV: casal } \\
\text { dançando, texto }\end{array}$ & $\begin{array}{l}-\hat{\delta} \\
\text { Brasileiro }\end{array}$ & $\begin{array}{l}\text { }+ \\
\text { Na educação }\end{array}$ & $\begin{array}{l}\text { Educação } \\
\text { Técnica } \\
\text { profissional } \\
\text { Mais de } 63 \text { mil } \\
\text { vagas }\end{array}$ & $\begin{array}{l}\text { [Estudantes } \\
\text { técnicos imitando } \\
\text { os passos do } \\
\text { mestre-sala e da } \\
\text { porta-bandeira; } \\
\text { boca: sorriso] }\end{array}$ \\
\hline 19 & 2 & $\begin{array}{l}\text { PC: E } \\
\text { PH: oblíqua } \\
\text { PV: baixa } \\
\text { D: média } \\
\text { CV: céu } \\
\text { azul, cesta de } \\
\text { basquete e } \\
\text { prédios } \\
\text { SV: cadeirantes, } \\
\text { texto }\end{array}$ & $-\delta$ O Brasil & $\begin{array}{l}\text { †- } \\
\text { Ena } \\
\text { qualidade de } \\
\text { vida. Porque } \\
\text { toda pessoa }\end{array}$ & $\begin{array}{l}\text { Educação } \\
\text { Técnica } \\
\text { profissional } \\
\text { Mais de } 63 \text { mil } \\
\text { vagas }\end{array}$ & $\begin{array}{l}\text { Cadeirantes } \\
\text { jogando basquete }\end{array}$ \\
\hline
\end{tabular}

Nesse quadro, temos três frames que mostram a utilização das políticas governamentais de crédito. Essa contextualização pode ser vista no texto escrito aposto à imagem, que indica dados estatísticos sobre a facilitação do recolhimento de imposto e a abertura de vagas para a educação. $\mathrm{O}$ acesso mais fácil ao crédito favorece o empreendedorismo e a formação do indivíduo. A voz da narradora e os dados apresentados na tela sobre o Supersimples, tipo de imposto com facilitação em relação ao pagamento, reforçam o sentido do mundo retratado nos frames visuais, nos quais o progresso constitui o marco principal. A política de inclusão é reforçada pelos grupos lexicais "qualidade de vida" e "toda pessoa", associadas e integradas ao quadro retratando o cadeirante atleta. 


\section{O pandeiro, a cuíca, a saúde comemorada pelo povo}

Quadro 8-A Roda de Samba

\begin{tabular}{|c|c|c|c|c|c|c|}
\hline $\mathrm{T}$ & $F R A M E$ VISUAL & $\begin{array}{l}\text { IMAGEM } \\
\text { VISUAL }\end{array}$ & $\begin{array}{l}\text { TRILHA } \\
\text { SONORA }\end{array}$ & $\begin{array}{l}\text { VOZ } \\
\text { FEMININA }\end{array}$ & $\begin{array}{l}\text { MODO } \\
\text { ESCRITA }\end{array}$ & $\begin{array}{l}\text { MOVIMENTO } \\
\text { CORPORAL }\end{array}$ \\
\hline 20 & & $\begin{array}{l}\text { PC: E } \\
\text { PH: oblíqua } \\
\text { PV: mediana } \\
\text { D: close } \\
\text { CV: camisa } \\
\text { branca } \\
\text { SV: pandeiro, } \\
\text { texto }\end{array}$ & $\begin{array}{l}\text { - }{ }^{7} \text { Tá forte } \\
\text { (coro de } \\
\text { sambistas) }\end{array}$ & ㅇ $\leqslant \mathrm{Tem}$ & $\begin{array}{l}\begin{array}{l}\text { Medicamentos } \\
\text { gratuitos }\end{array} \\
6,5 \text { milhões de } \\
\text { beneficiados }\end{array}$ & $\begin{array}{l}\text { Mão tocando } \\
\text { pandeiro }\end{array}$ \\
\hline 21 & les de & $\begin{array}{l}\text { PC: E } \\
\text { PH: frontal } \\
\text { PV: mediana } \\
\text { D: médio close } \\
\text { CV: roda de } \\
\text { samba } \\
\text { SV: camiseta } \\
\text { azul; senhora } \\
\text { sambista; texto }\end{array}$ & $\begin{array}{l}\text { - Ĵe tá } \\
\text { guerreiro } \\
\text { (coro de } \\
\text { sambistas) }\end{array}$ & $\begin{array}{l}+ \text { - } \\
\text { O direito de } \\
\text { vencer }\end{array}$ & $\begin{array}{l}\begin{array}{l}\text { Medicamentos } \\
\text { gratuitos }\end{array} \\
6,5 \text { milhões de } \\
\text { beneficiados }\end{array}$ & $\begin{array}{l}\text { [Mulher } \\
\text { sambando na } \\
\text { roda de samba; } \\
\text { sorriso] }\end{array}$ \\
\hline
\end{tabular}

A cena, bastante típica no contexto cultural e histórico da comunidade da classe média baixa no Brasil, especialmente no Rio de Janeiro, é a roda de samba no bar. Esse tipo de arranjo semiótico, com essas cenas, coloca em funcionamento nosso sistema de valores culturais, amplificadores do grau de empatia com o viewer: o pandeiro, a cuíca, a caipirinha, a feijoada, o toicinho, a cerveja, a música, o samba. As categorias mais relevantes para a formação do sentido do texto são o movimento corporal dos participantes e a trilha sonora, todas indexadas pelo close no instrumento e nas mãos do instrumentista. 


\section{A felicidade de se ter um emprego}

Quadro 9 - Ampliação da Oferta de Emprego

\begin{tabular}{|c|c|c|c|c|c|c|}
\hline $\mathrm{T}$ & FRAME VISUAL & $\begin{array}{l}\text { IMAGEM } \\
\text { VISUAL } \\
\end{array}$ & $\begin{array}{l}\text { TRILHA } \\
\text { SONORA } \\
\end{array}$ & $\begin{array}{l}\text { VOZ } \\
\text { FEMININA } \\
\end{array}$ & $\begin{array}{l}\text { MODO } \\
\text { ESCRITA }\end{array}$ & $\begin{array}{l}\text { MOVIMENTO } \\
\text { CORPORAL } \\
\end{array}$ \\
\hline 24 & & $\begin{array}{l}\text { PC: E } \\
\text { PH: oblíqua } \\
\text { PV: mediana } \\
\text { D: close médio } \\
\text { Cv: prédio ao } \\
\text { fundo } \\
\text { SV: celular e } \\
\text { maleta } \\
\text { FV: mediano; } \\
\text { fora de tela }\end{array}$ & $\begin{array}{l}-\precsim \text { Do } \\
\text { povo } \\
\text { (coro de } \\
\text { sambistas) }\end{array}$ & $\begin{array}{l}q-E m \\
2012\end{array}$ & $\begin{array}{l}\begin{array}{l}\text { Novos } \\
\text { empregos }\end{array} \\
2,2 \\
\text { milhões } \\
\text { (até } \\
\text { outubro) }\end{array}$ & $\begin{array}{l}\text { [Moça } \\
\text { executiva } \\
\text { falando ao } \\
\text { telefone com } \\
\text { uma maleta; } \\
\text { sorriso] }\end{array}$ \\
\hline 26 & $\begin{array}{l}\text { Novos Emprego } \\
2,2 \text { milhoes (ate ou }\end{array}$ & $\begin{array}{l}\text { PC: E } \\
\text { PH: frontal } \\
\text { PV: baixa } \\
\text { D: média } \\
\text { CV: árvores } \\
\text { SV: } \\
\text { trabalhadores, } \\
\text { roupa azul, } \\
\text { luvas brancas, } \\
\text { texto } \\
\text { FV: mediano; } \\
\text { viewer }\end{array}$ & $\begin{array}{l}-\bar{\delta} \\
\text { Brasileiro } \\
\text { (coro de } \\
\text { sambistas) }\end{array}$ & $\begin{array}{l}\text { +_-Vamos } \\
\text { manter o } \\
\text { ritmo }\end{array}$ & $\begin{array}{l}\text { Novos } \\
\text { empregos }\end{array}$ & $\begin{array}{l}\text { Supervisores } \\
\text { dançando; } \\
\text { sorriso }\end{array}$ \\
\hline
\end{tabular}

Com relação à representação dos participantes do Quadro 9, podemos dizer que a executiva, portadora da maleta, fala ao celular, dança e sorri; está feliz porque está empregada e porque, provavelmente, conseguiu uma promoção por conta da ajuda governamental para investimentos em cursos de especialização. A maleta é uma saliência visual e também um recurso semiótico. Em relação à saliência visual, podemos ressaltar o seu papel referencial e contextual - a maleta preta tem o significado de trabalho, de eficiência e de sucesso profissional. Roland Barthes dizia que tudo que aparece por resposta a uma prática social fica semiotizado: desde que haja sociedade, qualquer uso se converte em signo desse uso. O uso da capa de chuva é proteger da chuva, mas esse uso é indissociável do próprio signo de certa situação atmosférica (BARTHES, 2006 [1964], p. 44).

No último frame do Quadro 9, temos dois trabalhadores da construção civil comemorando, dançando e sorrindo, simultaneamente. Neste enquadre, a saliência é a cor azul, culturalmente indicadora de felicidade (vide, intertextualmente, a canção "Vesti azul. Minha sorte, então, mudou."). Podemos dizer que a cor azul, neste quadro, constrói uma avaliação visual (é bom termos empregos), ressaltando a metafunção interpessoal. Esse quadro está acompanhado de texto no modo escrita, com dados estatísticos referentes ao aumento no número da oferta de empregos. 


\section{A união entre o trabalho e a alegria}

Quadro 10 - O trabalho e a Diversão de Mãos Dadas e Braços Abertos

\begin{tabular}{|c|c|c|c|c|c|c|}
\hline $\mathrm{T}$ & FRAME VISUAL & $\begin{array}{l}\text { IMAGEM } \\
\text { VISUAL }\end{array}$ & $\begin{array}{l}\text { TRILHA } \\
\text { SONORA }\end{array}$ & $\begin{array}{l}\text { VOZ } \\
\text { FEMININA }\end{array}$ & $\begin{array}{l}\text { MODO } \\
\text { ESCRITA }\end{array}$ & $\begin{array}{l}\text { MOVIMENTO } \\
\text { CORPORAL }\end{array}$ \\
\hline 27 & & $\begin{array}{l}\text { PC: E } \\
\text { PH: oblíqua } \\
\text { PV: mediana } \\
\text { D: médio close } \\
\text { CV: máquina } \\
\text { amarela } \\
\text { SV: supervisores } \\
\text { de obra, capacete } \\
\text { branco } \\
\text { FV: vetor do } \\
\text { olhar liga dois } \\
\text { supervisores }\end{array}$ & & $\begin{array}{l}q \subseteq N a s \\
m \tilde{a} o s\end{array}$ & & $\begin{array}{l}\text { [Supervisores } \\
\text { dando as mãos; } \\
\text { sorriso] }\end{array}$ \\
\hline 28 & & $\begin{array}{l}\text { PC: E } \\
\text { PH: frontal } \\
\text { PV: mediana } \\
\text { D: médio close } \\
\text { CV: roda de } \\
\text { samba } \\
\text { SV: sambista, } \\
\text { braços abertos, } \\
\text { calça branca } \\
\text { FV: mediano: } \\
\text { viewer. }\end{array}$ & & $\begin{array}{l}\text { Drasileiro } \\
\text {-Do povo } \\
\text { brate }\end{array}$ & & $\begin{array}{l}\text { [Sambista de } \\
\text { braços abertos } \\
\text { sambando; } \\
\text { sorriso] }\end{array}$ \\
\hline
\end{tabular}

Novamente, o texto reforça o papel de coesão textual das mãos. No Quadro 10, no primeiro frame visual, podemos ver agora o significado da união (mãos unidas de, possivelmente, dois engenheiros civis) para a construção do Brasil. O frame visual final, reforçado semioticamente pela voz da narradora dizendo "do povo brasileiro", traduz, amplifica, transmite e perpetua a construção imagética do brasileiro típico — feliz, amigo, de braços abertos —, não esquecendo o vestuário: calças brancas, perfeitamente engomadas, e camisa estampada de mangas compridas, provavelmente de seda, o típico puxador de samba. 


\section{A Nação em nossas mãos}

Quadro 11 - A Marca, a Bandeira e o Slogo (slogan + logo)

\begin{tabular}{|c|c|c|c|c|c|c|}
\hline $\mathrm{T}$ & FRAME VISUAL & IMAGEM VISUAL & $\begin{array}{l}\text { TRILHA } \\
\text { SONORA }\end{array}$ & $\begin{array}{l}\text { VOZ } \\
\text { FEMININA }\end{array}$ & $\begin{array}{l}\text { MODO } \\
\text { ESCRITA }\end{array}$ & $\begin{array}{l}\text { MOVIMENTO } \\
\text { CORPORAL }\end{array}$ \\
\hline 29 & & \begin{tabular}{|l|} 
PC: E \\
PH: frontal \\
PV: alta \\
D: tomada em close \\
CV: fundo de madeira \\
SV: mãos, bandeira \\
nacional, cores \\
CR: verde e amarelo
\end{tabular} & & & & $\begin{array}{l}\text { Mãos de palma } \\
\text { para cima, lado } \\
\text { a lado, pintadas } \\
\text { com a bandeira } \\
\text { do Brasil. }\end{array}$ \\
\hline 30 & brasil.gov.bry & $\begin{array}{l}\text { PC: E } \\
\text { PH: frontal } \\
\text { PV: mediana } \\
\text { D: tomada média } \\
\text { CV: fundo branco } \\
\text { SV: slogo, cores } \\
\text { CR: verde e amarelo }\end{array}$ & & $\begin{array}{l}+- \\
\text { Governo } \\
\text { Federal }\end{array}$ & & \\
\hline
\end{tabular}

Assim como começou, o filme se encerra (Quadro 11) com a figura das mãos, desta vez, servindo de suporte para a pintura da bandeira do Brasil. Aparece, em seguida, o logo do Governo, com o slogan: País rico é país sem pobreza.

\section{A Interpretação — a identidade entre ideal e governo}

Como os recursos semióticos estão interligados nessa peça publicitária para formar o sentido do texto? O elemento específico que serve à coesão textual, presente em todo o texto e chegando a acarretar uma redundância significativa, são as mãos, que aparecem em grande parte dos frames visuais e na letra da música. Há uma significação metonímica do Brasil (parte pelo todo): as mãos dos brasileiros são o Brasil, e uma metáfora de construção/crescimento: as mãos dos brasileiros vão construir o Brasil e o País vai crescer. Nesse caso, o Brasil encontra-se metaforicamente conectado à produção agrícola (rapidamente, no primeiro frame visual); à construção civil (mais representativa) e às atividades de produção de bens e serviço dos microempresários (também representativa). Também são apresentadas tomadas com frames visuais ligados à educação, à saúde, ao crescimento 
do consumo. Os movimentos corporais (cinestésicos) acompanham o ritmo da música e, algumas vezes, a letra da música e a voz da narradora, como pôde ser visto horizontalmente na tabela (espécie de matriz insumo/produto, ou melhor, matriz recurso semiótico/sentido). No momento em que a narradora diz "o Brasil cresce", simultaneamente, para o viewer, aparece of frame visual em que a mãe levanta o filho até o alto.

A cena prototípica do Brasil é a roda de samba na mesa do bar. Isso coloca em funcionamento todo um sistema de valores culturais que aumentam o grau de empatia com o viewer: o pandeiro, a cuíca, a caipirinha, a feijoada, o toicinho, a cerveja, a música, o samba. As categorias mais relevantes para a formação do sentido do texto são o movimento corporal dos participantes e a trilha sonora.

As cenas de movimento no trabalho (pedreiro, marceneiro) persuadem o brasileiro telespectador (viewer) de que devemos trabalhar para construir uma grande nação. Podemos considerar todos os movimentos como movimentos de propostas, ou melhor, como metáforas visuais interpessoais. Há uma orientação dialógica no movimento, que se constitui metaforicamente como um modo de expressão para a proposta. O movimento é feito como uma oferta para o outro, com uma disposição afetiva do atuador: alegria, entusiasmo. O movimento corporal e a expressão facial dos participantes podem ser vistos como uma recontextualização de movimentos feitos por outros participantes das práticas sociais: caixinha de fósforo recontextualizando o movimento do músico do pandeiro; estudantes imitando a coreografia da porta-bandeira e do mestre-sala; microempresário da padaria atuando como sambista. Segundo Baldry e Thibault (2002), o movimento pode ser executado naturalmente, artificialmente ou apropriadamente. Na peça publicitária, os movimentos não são apropriados no que diz respeito às circunstâncias em que eles ocorrem. (sambar na sapataria, sambar na padaria, dançar na escola técnica). Esse tipo de deslocamento (recontextualização de práticas sociais) pode favorecer o fortalecimento do ideal brasileiro de ser muito alegre o tempo todo, inclusive no trabalho ou na escola.

Também é retratado o acesso feliz ao consumo (mulher na sapataria); a certeza no futuro, com a mãe levantando o filho que vai crescer; e a alegria de viver, com a senhora dançando na roda de samba. Tudo isso porque têm mais acesso aos medicamentos, distribuídos gratuitamente (o texto escrito, com os dados da distribuição de medicamentos, sobrepõe-se a esses frames visuais).

Todos os participantes estão sorrindo. Alguns interagem com o viewer, outros, não, mas todos estão felizes, comemorando, sambando (e a voz da narradora confirma: "Tá todo mundo celebrando"). O participante/ator mais saliente é o gari, o dono da tomada mais longa. Ele é apresentado inicialmente como uma sombra (suspense) e, após essa tomada, samba em frente a um sobrado onde há um senhor encostado em uma cadeira, batucando com a mão. O gari é símbolo do samba, porque é ele que varre a imensa área do sambódromo, completamente abarrotada de lixo após o carnaval. O texto torna o gari um protagonista desse ideal de Nação, além de realizar o paralelo entre trabalho e alegria - todos os trabalhadores estão alegres em trabalhar, em alcançar as suas metas, que são as metas do Brasil.

O contexto mais saliente são as rodas de samba, onde há o batuque. O batuque inicia o texto (batuque da caixa de fósforo) e fecha o texto na forma dos braços abertos do sambista 
(em frente a uma roda de samba), indicando ao viewer (telespectador) que este faz parte do mundo retratado. Pouco antes do aparecimento do slogo (slogan + logo) do Governo Federal, são mostradas as palmas de duas mãos formando a bandeira nacional, o que confirma o Brasil (representado metonimicamente pela bandeira) situado nas mãos do trabalhador brasileiro.

Esse é o pano de fundo para que a voz feminina, portadora principalmente da metafunção interpessoal, possa realizar uma troca de serviço (novamente uma metáfora interpessoal) com o ouvinte/viewer, dando-lhe uma ordem, especialmente quando diz: "Em 2012 vamos manter o ritmo". Essa é uma metáfora interpessoal, isto é, uma ordem é dada sob forma de afirmação no tempo futuro. O ritmo a que a locutora se refere é o ritmo de crescimento e de trabalho, mas está sincronizado, metaforicamente, ao ritmo do samba.

O sentido acional realizado pelo texto, via gênero propaganda, é muito claro. Há um convite ao viewer (telespectador) para se identificar com aquele ideal brasileiro: trabalhador, sorridente, amável, amante do samba. Esse ideal brasileiro transforma-se, para o viewer, no objetivo a ser atingido, e esse objetivo é o que vai unir todos os brasileiros em uma irmandade alegre, sambista e trabalhadora. Esse ideal vai dar a liga de que o governo precisa para atingir o controle social necessário para a governança.

Por meio dessa peça publicitária, podemos ver a equivalência entre governo e Brasil e entre governo e povo. A questão não é o Estado brasileiro, mas o governo brasileiro, que precisa ser identificado com o ideal brasileiro, construído pelo texto, que é um texto dinâmico, um filme. Assim, o caminho do transporte semiótico por nós sugerido é este: mãos - samba trabalho - consumo - educação - saúde - alegria - ideal brasileiro - governo. Dessa forma, o governo é identificado com o ideal brasileiro e, assim, pode unir toda a população.

O típico ideal brasileiro - sorridente, sambista — já vem sendo construído em nossa história e ao longo de nossa formação cultural. Nas copas do mundo e no carnaval, isso é muito explorado pelos anunciantes, assim como a Copa de 70 o foi pela Ditadura Militar. Acreditamos que esse ideal brasileiro atual — sorridente, sambista e trabalhador — está sendo muito considerado pelo governo, cujas peças publicitárias se caracterizam pela apresentação de políticas sociais e econômicas como dádivas para que a população seja persuadida de que pertence a uma comunidade coesa, que pode ser melhor controlada.

Cada narrativa convida o viewer a ver a si próprio, a identificar ali o seu ideal identitário. Isso também é conseguido graças ao predomínio de orações relacionais, que constroem metáforas, base da construção de configurações identitárias ideais. O olhar do sambista (último) para o viewer, integrado ao seu movimento corporal (cinestesia) de abrir os braços, referencia a identidade que existe entre o viewer e o sambista. Os personagens são espelhos, na frente do qual o viewer se mira e se admira.

As profissões apresentadas no texto (agricultor, pedreiro, marceneiro, gari, recepcionista de hotel) realmente são valiosas para o desenvolvimento de qualquer país, mas não há, no Brasil, a cultura de se remunerar bem esse tipo de profissão. De modo geral, o pedreiro, o marceneiro, o gari e o pequeno agricultor ganham abaixo do valor da remuneração percebida em outras nações. Entretanto, graças à trilha sonora e à integração de todos os recursos semióticos, essas profissões ficam engrandecidas, idealizadas. 


\section{O Sistema de Transitividade}

Há prevalência de orações relacionais no que diz respeito ao sistema de transitividade nos textos do modo fala. As orações relacionais são aquelas que constroem conceitos e ligam duas entidades semióticas. O resultado dessa ligação é uma nova entidade semiótica. As orações relacionais são responsáveis pela formação de metáforas, figuras de linguagem primordiais nas construções discursivas e no trânsito das ideologias. Os textos da voz da narradora e da letra do samba são compostos, principalmente, de orações relacionais, (intensivas, possessivas e circunstanciais), com a construção de imagens ideais do Brasil, já presentes em outros textos, como no Hino Nacional, por exemplo.

A seguir, temos o quadro das orações relacionais presentes na letra da canção e no texto da narradora. Podemos perceber, com base nesse quadro, que o principal portador desses processos relacionais é o "Brasil", confirmando a função de formação de identidade da peça publicitária governamental, além de sua função persuasiva. Nossa percepção (nós, como viewers do comercial) fica invadida pelas afirmações construtoras da identidade do Brasil, realçadas e reforçadas pelo ritmo musical.

Quadro 12 - As Orações Relacionais

\begin{tabular}{|c|c|c|c|}
\hline O Brasil & \multicolumn{2}{|l|}{ está } & $\begin{array}{l}\text { em boas mãos/nas mãos do } \\
\text { povo brasileiro }\end{array}$ \\
\hline Portador & \multicolumn{2}{|c|}{$\begin{array}{l}\text { processo relacional circunstancial } \\
\text { atributivo }\end{array}$} & circunstância (lugar) \\
\hline O Brasil & \multicolumn{2}{|l|}{ está } & forte \\
\hline Portador & \multicolumn{2}{|c|}{ processo relacional intensivo atributivo } & atributo \\
\hline O Brasil (implícito) & \multicolumn{2}{|l|}{ está } & guerreiro \\
\hline Portador & \multicolumn{2}{|c|}{ processo relacional intensivo atributivo } & atributo \\
\hline Tá (estar) & \multicolumn{2}{|l|}{ todo mundo } & $\begin{array}{l}\text { celebrando (muito perto da } \\
\text { função adjetiva) }\end{array}$ \\
\hline $\begin{array}{l}\text { Processo relacional } \\
\text { intensivo atributivo }\end{array}$ & \multicolumn{2}{|l|}{ portador } & atributo \\
\hline O Brasil & cresce & $\begin{array}{l}\text { com mais } \\
\text { oportunidades }\end{array}$ & $\begin{array}{l}\text { na produção, na educação, } \\
\text { na saúde. }\end{array}$ \\
\hline Existente & processo existencial & circunstâncias modais & circunstâncias de lugar \\
\hline (porque) Toda pessoa & \multicolumn{2}{|l|}{ tem } & o direito de vencer \\
\hline Possuidor & \multicolumn{2}{|c|}{ processo relacional possessivo } & possuído. \\
\hline
\end{tabular}


As orações relacionais são recursos semióticos para construir metáforas e também para fazer avaliações. Essas avaliações auxiliam no construto do ideário imaginário do brasileiro feliz, bem-humorado e determinado (tá todo mundo celebrando; o Brasil tá forte, tá guerreiro). Podemos ver o envolvimento acrítico a esse ideal brasileiro alegre (o sorriso é um elemento importante de coesão textual) e amante do samba. No filme, os participantes convidam o viewer a fazer parte dessa comunidade: convidam com o sorriso e com o movimento corporal, culminando com o sambista recebendo o viewer com um sorriso e de braços abertos.

\section{A Intertextualidade: o Hino Nacional}

As metáforas (de guerra, principalmente) fazem intertextualidade com a letra do Hino Nacional, confirmação de que os recursos semióticos são cultural e historicamente moldados. Vamos analisar as metáforas históricas a seguir.

Quadro 13 - Metáforas de Guerra e Intertextualidade com o Hino Nacional

- Guerra: O Brasil está forte e está guerreiro.

- Guerra: Porque toda pessoa tem o direito de vencer.

- Interdiscursividade com o Hino Nacional:

- O Brasil está forte e está guerreiro/És belo, és forte, impávido colosso,(...)

- Porque toda pessoa tem o direito de vencer/verás que um filho teu não foge à luta.

A intertextualidade revela a memória cultural que pode ser ativada em vários outros textos. A concepção do Brasil como um guerreiro faz parte do nosso ideário identificador. Há uma antinomia na constituição da identidade do brasileiro: o guerreiro versus o bonachão sorridente. Essa antinomia é, de certa forma, "costurada" nos movimentos de dança e de comemoração ao longo do filme. Os movimentos e as expressões faciais retratam o contexto cultural da atualidade do Brasil, configurando-se em primeiro plano para modelar e para realçar o convite a pertencer à comunidade dos brasileiros. O sorriso expressa uma das marcas da cultura brasileira e é um elemento de coesão textual.

\section{Considerações finais}

$\mathrm{O}$ design realiza grande parte do significado textual. $\mathrm{O}$ autor/meaning maker constrói o seu texto de acordo com o seu interesse, utilizando os diversos recursos semióticos moldados culturalmente para configurar o design do seu texto. Segundo Kress (2010), o design pode ser 
identificado como a deliberação sobre a escolha dos modos de representação e do framing para aquela representação.

O design realiza relações sociais; na realização em textos ele também projeta e constrói relações sociais. Cada instância do design de um texto é o resultado de escolhas, cada traço escolhido se torna um signo de (aspectos de) relação social. Cada escolha feita realiza um aspecto da relação social imaginada (e para ser projetada). Escolha, neste como em todos os ambientes, é moldada pelo poder: o poder de atribuir uma posição social para quem vai se envolver com o texto. Cada escolha é um ato político (KRESS, 2010, p. 139, grifo nosso).

A análise do texto permite dizer que há identificação entre governo e povo brasileiro, porque "estar nas mãos de" significa "ser governado por", e esse paralelismo entre governo e povo brasileiro pode ser reafirmado por meio dos dois últimos frames visuais, nos quais aparecem mãos de palmas para cima pintadas com a bandeira brasileira e, em seguida, o slogo $(\operatorname{sog} a n+\operatorname{logo})$ do Governo Federal, com as cores da bandeira nacional. É plausível dizer que o comercial sugere o governo localizado nas mãos do povo brasileiro. Assim, o povo brasileiro sente-se incluído no governo. O texto mostra um convite para que o povo se sinta dono e construtor do Brasil, o que torna a população mais facilmente governável.

Após análise dos processos de transmissão de visões de mundo, podemos dizer que o modo de operação da ideologia, segundo a classificação de Thompson (1990), é a unificação por meio da estratégia de construção simbólica chamada simbolização da unidade. Tal construção se dá com a construção de símbolos de unidade e de identificação coletiva. É possível ver como a identidade e os valores nacionais são manipulados nessa peça publicitária.

O sentido do texto é construído por meio do arranjo de uma série de recursos semióticos (imagem, música, cor, voz, escrita, movimento do corpo, expressão facial) que, ritmicamente integrados, materializam os significados. As marcas da chamada identidade nacional (sorriso, samba, batuque) são reafirmadas e retransmitidas, sendo reiteradas em várias peças publicitárias em época de copa e de olimpíada, o que ajuda a obscurecer os problemas sociais do Brasil. Nesse sentido, a matriz de transcrição textual proposta por Baldry e Thibault constitui ferramenta fundamental para a interpretação de vídeos porque permite a configuração de uma percepção lógico-semântica indicadora e explicitadora tanto da simultaneidade na utilização de recursos semióticos, quanto de sua sucessão ao longo da linha temporal na qual se encontra o fluxo textual. 


\section{Referências}

BARTHES, R. Elementos de semiologia. São Paulo: Cultrix: 1964/2006.

FAIRCLOUGH, N. Analysing discourse: textual analysis for social research. London: Routledge, 2003.

HALLIDAY, M.A.K. An introduction to functional grammar. London: Hodder Education, 2004.

KRESS, G. Multimodality: a social semiotic approach to contemporary communication. London: Routledge, 2010.

O BRASIL ESTÁ EM BOAS MÃOS. Vídeo de publicidade institucional do governo brasileiro, lançado em 2011, como campanha de fim de ano. Secretaria de Comunicação Social. Disponível em: <http:// www.secom.gov.br/sobre-a-secom/publicidade/campanhas-de-publicidade-institucional/o-brasil-estaem-boas-maos.-nas-maos-do-povo-brasileiro> Acesso em: 26 mar. 2012.

THIBAULT, P. J.; BALDRY, A. Multimodal transcription and text analysis: a multimedia toolkit and coursebook. London: Equinox, 2010.

THOMPSON, J.B. Ideology and modern culture. Stanford: Stanford University Press, 1990. 
